\title{
Fibroblast growth factor 2 is a key determinant of vascular sprouting during bovine luteal angiogenesis
}

\author{
Kathryn J Woad ${ }^{1,2}$, Morag G Hunter ${ }^{1}$, George E Mann ${ }^{1}$, Mhairi Laird ${ }^{1}$, Amanda J Hammond ${ }^{1}$ \\ and Robert S Robinson ${ }^{2}$ \\ ${ }^{1}$ School of Biosciences and ${ }^{2}$ School of Veterinary Medicine and Science, University of Nottingham, Sutton Bonington \\ Campus, Loughborough, Leicestershire LE12 5RD, UK
}

Correspondence should be addressed to KJ Woad at School of Veterinary Medicine and Science, University of Nottingham; Email: katie.woad@nottingham.ac.uk

\begin{abstract}
Fibroblast growth factor (FGF) 2 and vascular endothelial growth factor (VEGF) A are thought to be key controllers of luteal angiogenesis; however, their precise roles in the regulation and coordination of this complex process remain unknown. Thus, the temporal and spatial patterns of endothelial network formation were determined by culturing mixed cell types from early bovine corpora lutea on fibronectin in the presence of FGF2 and VEGFA ( $6 \mathrm{~h}$ to 9 days). Endothelial cells, as determined by von Willebrand factor immunohistochemistry, initially grew in cell islands (days 0-3), before undergoing a period of vascular sprouting to display a more tubule-like appearance (days 3-6), and after 9 days in culture had formed extensive intricate networks. Mixed populations of luteal cells were treated with SU1498 (VEGF receptor 2 inhibitor) or SU5402 (FGF receptor 1 inhibitor) or control on days 0-3, 3-6 or 6-9 to determine the role of FGF2 and VEGFA during these specific windows. The total area of endothelial cells was unaffected by SU1498 treatment during any window. In contrast, SU5402 treatment caused maximal reduction in the total area of endothelial cell networks on days 3-6 vs controls (mean reduction $81 \% ; P<0.001)$ during the period of tubule initiation. Moreover, SU5402 treatment on days 3-6 dramatically reduced the total number of branch points $(P<0.001)$ and degree of branching per endothelial cell island $(P<0.05)$ in the absence of changes in mean island area. This suggests that FGF2 is a key determinant of vascular sprouting and hence critical to luteal development.

Reproduction (2012) 143 35-43
\end{abstract}

\section{Introduction}

The corpus luteum $(\mathrm{CL})$ requires an extensive vascular supply to support its rapid growth and steroidogenic function and inadequate progesterone production has been associated with poor embryo development and increased pregnancy failure in the cow (Larson et al. 1997, Mann \& Lamming 2001). Angiogenesis, the development of a new blood supply, is a tightly regulated process driven and controlled by both pro- and antiangiogenic factors.

Vascular endothelial growth factor (VEGF) $\mathrm{A}$ is a potent stimulator of vascular endothelial cell proliferation and migration (Ferrara 2004). Furthermore, VEGFA is present in the bovine $\mathrm{CL}$ at high concentrations that remain constant throughout luteal development (Robinson et al. 2007) and stimulates luteal angiogenesis in vitro (Robinson et al. 2008). In several species, including the cow, the periovulatory inhibition of VEGFA activity markedly suppressed luteal function and vascularity in vivo (Fraser et al. 2000, Wulff et al. 2001, Yamashita et al. 2008).
Fibroblast growth factor (FGF) 2 also exerts a range of pro-angiogenic actions (Presta et al. 2005). FGF2 stimulates the proliferation of endothelial cells derived from bovine corpora lutea (Gospodarowicz et al. 1986) and is expressed at particularly high levels during the bovine follicular-luteal transition (Robinson et al. 2007). Moreover, local neutralisation of FGF2 by direct injection of FGF2 antibody into the developing bovine $\mathrm{CL}$ altered luteal growth and function, as demonstrated by reductions in luteal volume and steroid synthesis (Yamashita et al. 2008).

Recently, we have developed a novel primary cell culture system derived from early corpora lutea that simulates luteal angiogenesis (Robinson et al. 2008). In this system, the various cell types of the $\mathrm{CL}$ are cultured together, resulting in both $\mathrm{LH}$-induced progesterone production and endothelial cell network formation which is highly responsive to angiogenic stimuli (Robinson et al. 2008, Woad et al. 2009). The continuous inhibition of FGF2 or VEGFA signalling in this system dramatically reduces luteal endothelial cell network formation (Woad et al. 2009). However, it 
remains unclear whether there are key periods and processes during luteal angiogenesis that are acutely dependant on growth factor stimulation.

The aim of this study was 1 ) to determine the spatial and temporal patterns of endothelial cell network growth using this in vitro model of bovine luteal angiogenesis and 2) to investigate which of these stages of growth were most sensitive to inhibition of VEGFA and FGF2. We hypothesised that inhibition of FGF2 activity would be most critical during the early periods of luteal angiogenesis, whilst VEGFA activity would be required throughout all stages of angiogenesis.

\section{Results}

\section{Development of endothelial cell networks over time}

Endothelial cells were detected by immunostaining for von Willebrand factor (VWF) throughout culture, from the earliest time point $(6 \mathrm{~h})$ to day 9 . Endothelial cells were initially identified in islands of several cells (Fig. 1A). Multiple islands were present across each field of view, and were most often separated from each other and from other cells (Fig. 1B). These islands grew in size over the first day of culture to often contain 20 or more endothelial cells by day 2 (Fig. 1C-E). The endothelial cells were closely apposed within the islands and appeared polygonal in shape (Fig. 1E). With subsequent cell proliferation the endothelial cell islands became densely packed and surrounded by other luteal cell types (Fig. $1 \mathrm{~F}$ and $\mathrm{G}$ ). Tubule-like extensions then began to sprout from the endothelial islands, often displaying simple branch points (Fig. $1 \mathrm{H}$ ). On the later days of culture fewer endothelial islands were observed, and the majority of endothelial cells were present in extensive complex networks (Fig. 1I-L), with multiple branch points and interconnections between adjacent networks reminiscent of a primitive capillary plexus (Fig. $1 \mathrm{~K}$ and $\mathrm{L}$ ).

The timing of the inhibitor treatment windows was chosen following the detailed observation of endothelial cell growth from days 0 to 9 in culture. The first window (days $0-3$ ) was primarily associated with the period of endothelial island formation. The subsequent window on days 3-6 of culture was associated with considerable reorganisation and changes in phenotype as the endothelial cell islands began to be replaced by tubule-like structures, and this window was characterised by the process of vascular sprouting and endothelial tubule initiation. The final window (days 6-9) was primarily a period of network development, with endothelial cell networks becoming larger and more complex.
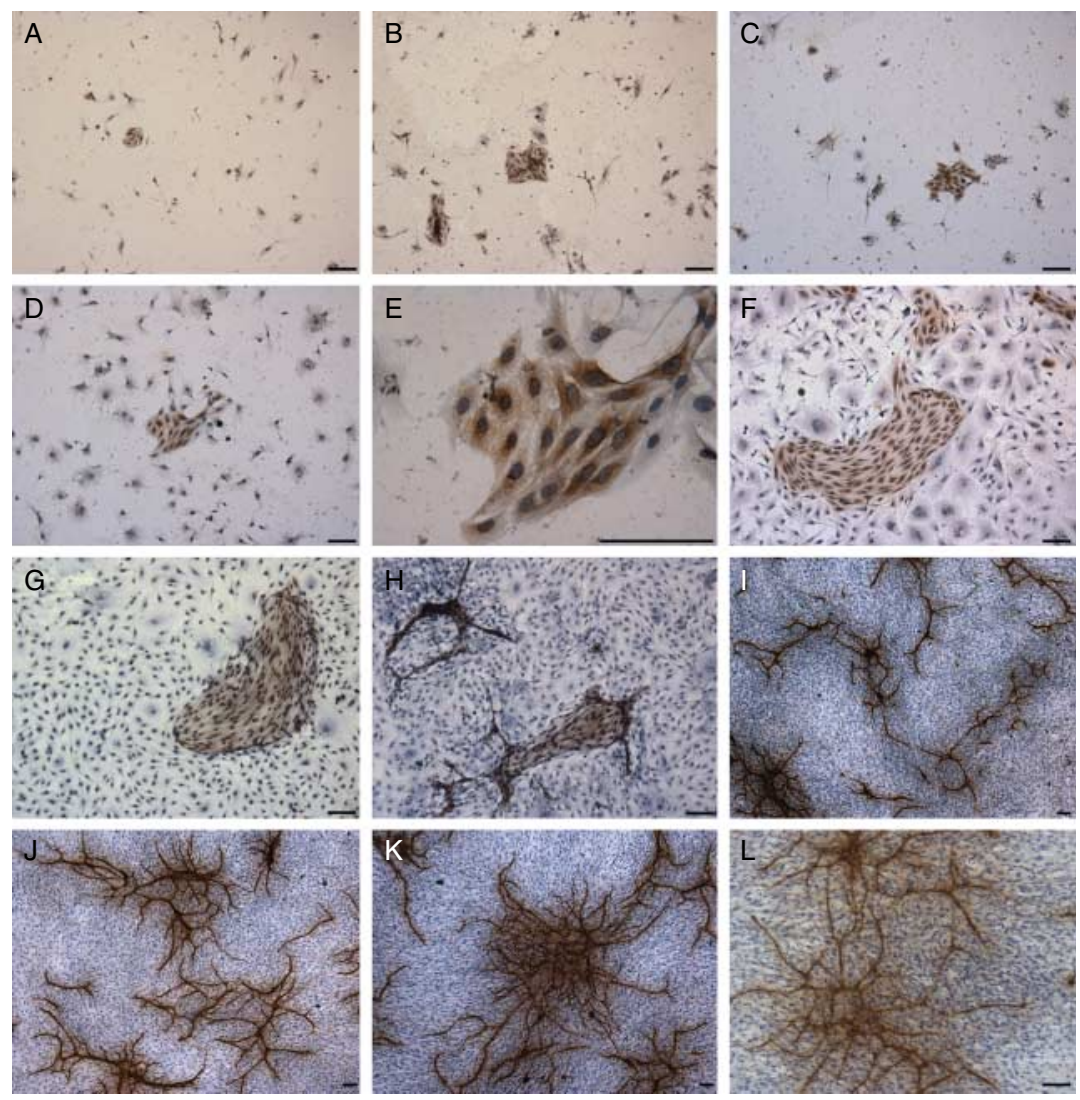
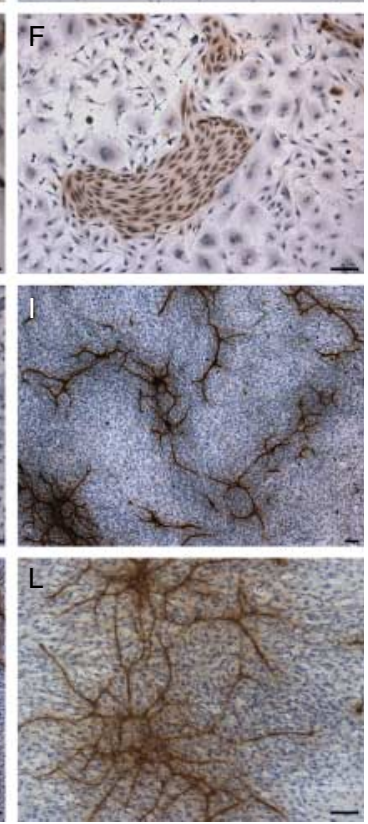

Figure 1 Time course of bovine luteal angiogenesis in vitro, showing endothelial cell growth between $6 \mathrm{~h}$ and 9 days. Endothelial cells were immunolocalised by von Willebrand factor staining (brown) after (A) 6, (B) 12 and (C) $18 \mathrm{~h}$ (day 1 ) and then every $24 \mathrm{~h}$; day $2(\mathrm{D}$ and $\mathrm{E})$, day $3(\mathrm{~F})$, day $4(\mathrm{G})$, day $5(\mathrm{H})$, day $6(\mathrm{I})$, day $7(\mathrm{~J})$, day $8(\mathrm{~K})$ and day $9(\mathrm{~L})$. Bar represents $100 \mu \mathrm{m}$. 


\section{Sensitive periods during endothelial network formation; response to timed inhibitor treatments}

Extensive endothelial cell networks were observed in control wells after 9 days in culture (Fig. 2A). Quantification of the VWF staining revealed an effect of treatment with $1 \mu \mathrm{M}$ SU5402 (specific FGF receptor 1 (FGFR1) inhibitor) on the total area of endothelial cell networks vs controls (Fig. 3A; $P<0.001$ ). Treatment with SU5402 on days $0-3$ or 3-6 of culture reduced the total area of endothelial cell networks compared with control levels (Fig. 2A-C; $P<0.05$ ), whilst treatment on days 6-9 did not significantly alter endothelial cell network area (Fig. 2A and D; $P>0.05$ ). The total area of endothelial cell networks was maximally reduced by $81 \%$ on days 3-6 (Fig. 3A) and by around 64\% following SU5402 treatment on days $0-3$ (Fig. 3A) vs controls.

The reduction in the total area of endothelial cell networks after treatment with SU5402 was principally a result of a reduction in the mean number of networks (Fig. 3B; $P<0.001$ ) rather than the mean area of each network, which was unaffected by treatment at any time point (Fig. 3B; $P>0.05$ ). The total length of endothelial cell networks was also reduced by treatment with SU5402 $(P<0.001)$ in a pattern similar to that observed for reductions in the total area of VWF staining (data not shown).
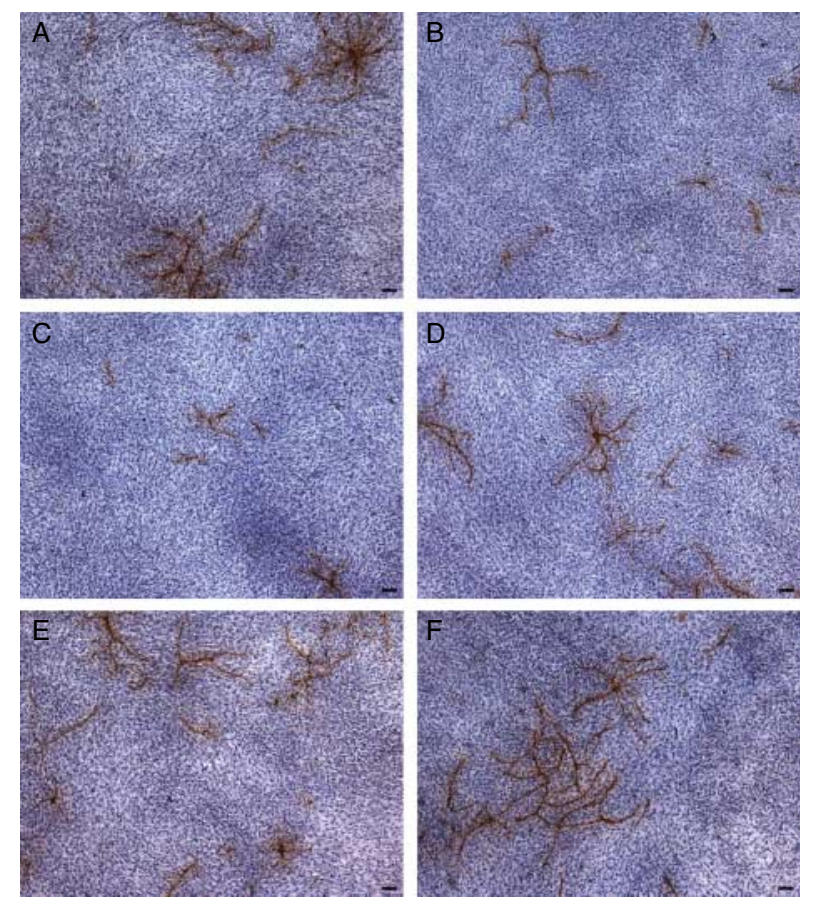

Figure 2 Representative images of bovine luteal cells treated with control medium (A and E) or plus $1 \mu \mathrm{M}$ SU5402 (FGFR1 inhibitor) for (B) days 0-3, (C) days 3-6, (D) days 6-9 or $2 \mu \mathrm{M}$ SU1498 (VEGFR inhibitor) for $(F)$ days 3-6. Endothelial cells were immunostained for von Willebrand factor (brown) after 9 days of culture. Bar represents $100 \mu \mathrm{m}$.
The total area of VWF staining was not reduced by treatment with $2 \mu \mathrm{M}$ SU1498 (specific VEGF receptor 2 (VEGFR2) inhibitor) to inhibit VEGFA signalling during any time window (Figs $2 \mathrm{E}$ and $\mathrm{F}$ and $3 \mathrm{C} ; P=0.86$ ).

\section{Inhibition of FGF2 signalling reduces endothelial sprouting}

Treatment with SU5402 on days 3-6 followed by fixation on day 6 (as opposed to day 9) reduced the total area of endothelial cell staining by around $79 \%$ vs day 6 controls (Fig. $4 \mathrm{~A}-\mathrm{C} ; P<0.001$ ) as a result of a $68 \%$ reduction in the mean number of endothelial islands (data not shown; $P<0.001)$, whilst the mean area per endothelial island was unaffected by FGFR1 inhibitor treatment (Fig. 4D; $P=0.05)$. The degree of vascular sprouting was determined by branch point analysis; this demonstrated a $90 \%$ reduction in the total number of endothelial branch points following SU5402 treatment vs controls (Fig. 4A, B and E; $P<0.001$ ). Moreover, treatment with SU5402 also reduced the mean number of branch points measured per individual endothelial cell island from around 3.4 to 1.2 (Fig. $4 \mathrm{~A}, \mathrm{~B}$ and $\mathrm{F} ; \mathrm{P}<0.05$ ).

\section{Discussion}

We have previously demonstrated that the blanket inhibition of FGF2 or VEGFA signalling results in dramatic reductions in bovine luteal endothelial cell network formation (Woad et al. 2009). In this study, we utilised our in vitro model of angiogenesis to further investigate the regulation of luteal angiogenesis; employing inhibitors of FGF2 and VEGFA activity at key time points during culture, to determine the specific periods of growth factor sensitivity or dependence.

Treatment with SU5402, a specific FGFR1 inhibitor, reduced the total area of VWF immunostaining maximally on days $3-6$ (81\% reduction), also reduced staining on days $0-3$ ( $64 \%$ reduction) and had no effect on days 6-9 of culture vs controls. This indicates that the days 3-6 window is a key period of sensitivity to FGF2 regulation in culture. We have previously shown that FGF2 is particularly dynamic around the follicular-luteal transition and FGF2 protein concentrations are highest in the collapsed follicle immediately post-ovulation (Robinson et al. 2007). Therefore, this study provides further evidence to support an important role for FGF2 in the early stages of bovine luteal angiogenesis.

SU5402 is a narrow-range tyrosine kinase inhibitor that has been extensively used to specifically inhibit FGF2 signalling. The FGFR gene family is comprised four members (FGFR1-FGFR4) and alternative splicing events result in numerous receptor isoforms. Whilst the interaction of SU5402 with FGFR1 has been studied in detail, similarity in the sequence and structure of the catalytic domains of FGFRs suggests that SU5402 may also inhibit the phosphorylation of additional FGFRs. 


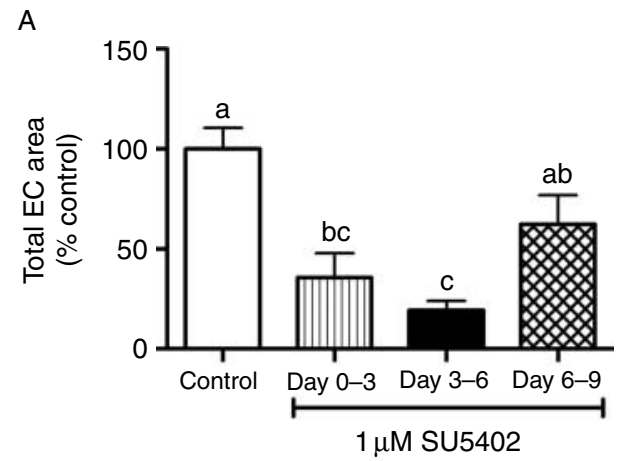

B
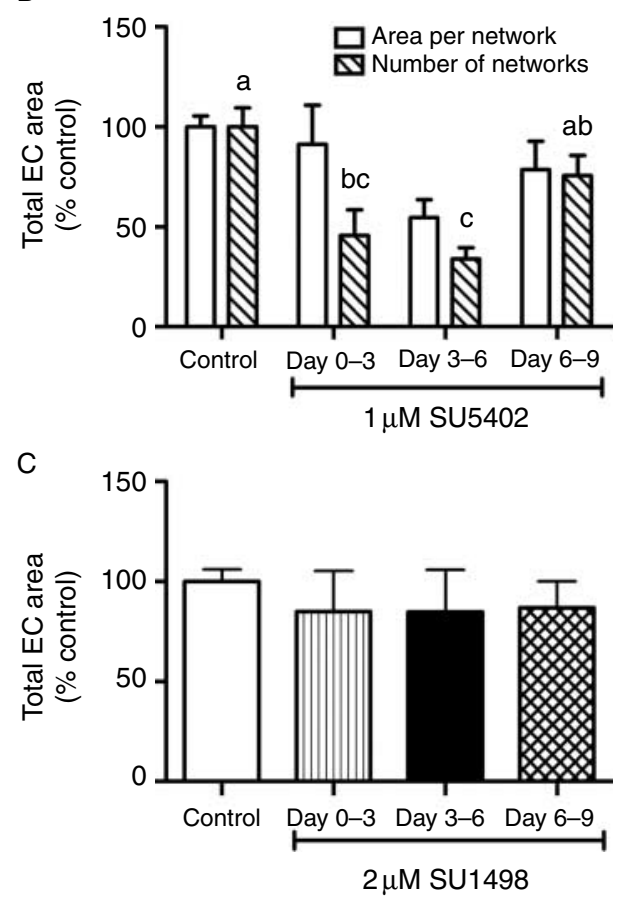

Figure 3 Dispersed cells from early bovine corpora lutea were treated with either control medium for 9 days, or plus $1 \mu \mathrm{M}$ SU5402 FGFR1 inhibitor; ( $A$ and B) or plus $2 \mu$ M SU1498 VEGFR2 inhibitor; (C) for days $0-3,3-6$ or $6-9$. Cover slips were fixed on day 9 and endothelial cells were localised by von Willebrand factor immunostaining. Following quantification and image analysis the effects of inhibitors are shown on (A and C) the total endothelial cell (EC) area and (B) the mean area of each network and the mean number of endothelial networks. Data are mean + S.E.M. Significant differences between the groups $(P<0.05)$ are indicated by different letters; $a>b>c$.

Indeed, SU5402 inhibited the phosphorylation of FGFR2 (variant B) in bladder carcinoma cells (Bernard-Pierrot et al. 2004) and the growth of multiple myeloma cells with activating mutations of FGFR3 (Grand et al. 2004).

The FGF ligands show different affinities for different FGFR isoforms; FGF2 preferentially activates FGFR1C, FGFR3C and FGFR4, and to a lesser degree activates FGFR1B and FGFR2C (Ornitz et al. 1996). The bovine CL has been shown to express negligible levels of FGFR3C and FGFR4 (Guerra et al. 2008), and hence the most likely luteal targets of FGF action are variants of FGFR1 and FGFR2. FGFR2C mRNA expression did not vary with bovine luteal development in vivo (Guerra et al. 2008) and it is not known whether or to what degree FGF2 might be signalling via FGFR2C in our culture system, or what relative contribution this might make to the regulation of angiogenesis.

The time windows of inhibitor treatment were chosen to correspond to different periods of endothelial cell growth and development in culture; days $0-3$ are characterised by the growth of endothelial cells predominantly in dense island formations. The window between days 3 and 6 represents a phase of rapid reorganisation characterised by vascular sprouting and the initiation of tubule-like growth and the final window between days 6 and 9 appears primarily to be a time of further endothelial cell network development and increasing complexity. The maximal response to FGF2 inhibition on days 3-6 corresponds to the period when endothelial tubules are first observed and suggests a role for FGF2 in the initiation of endothelial cell sprouting.

A role for FGF2 in endothelial cell sprouting was further supported by the changes in growth pattern that were observed on day 6 after treatment with SU5402 on days $3-6$. FGFR1 inhibition resulted in a $90 \%$ reduction in the total number of endothelial branch points. This reflects both reduced island number and a dramatic reduction in the mean number of vascular sprouts observed per island, which occurred in the absence of a reduction in mean island area.

In order for a vascular network to grow, a subset of cells at the tip of an emerging vascular sprout must acquire a specialised phenotype that distinguishes them from the remaining stalk cells (Eilken \& Adams 2010). The endothelial tip cells then undergo directional growth enabled by filopodia extensions and guided by angiogenic stimuli. Motile tip cells eventually make connections with other adjacent vessels and fuse together, meanwhile endothelial cell proliferation is thought to be predominantly occurring in the stalk cell population (Gerhardt et al. 2003). Whilst the time periods in culture may not directly correlate with similar time periods of luteal development in vivo, these early steps in angiogenesis are reproduced in our luteal model, leading to the establishment of complex endothelial cell networks.

There is remarkably little information about the specific role(s) FGF2 plays in determining sprouting during angiogenesis. Nevertheless, exposure to FGF2 did increase the density and branching of the vascular tree of the chorioallantoic membrane (Parsons-Wingerter et al. 2000) and transgenic mice expressing a dominantnegative FGFR1 displayed a diminished retinal vasculature with reduced branching (Rousseau et al. 2000). Based on the properties of FGF2, its role may include promoting endothelial cell proliferation, motility or the extension of filopodia and clearly this warrants further investigation. 

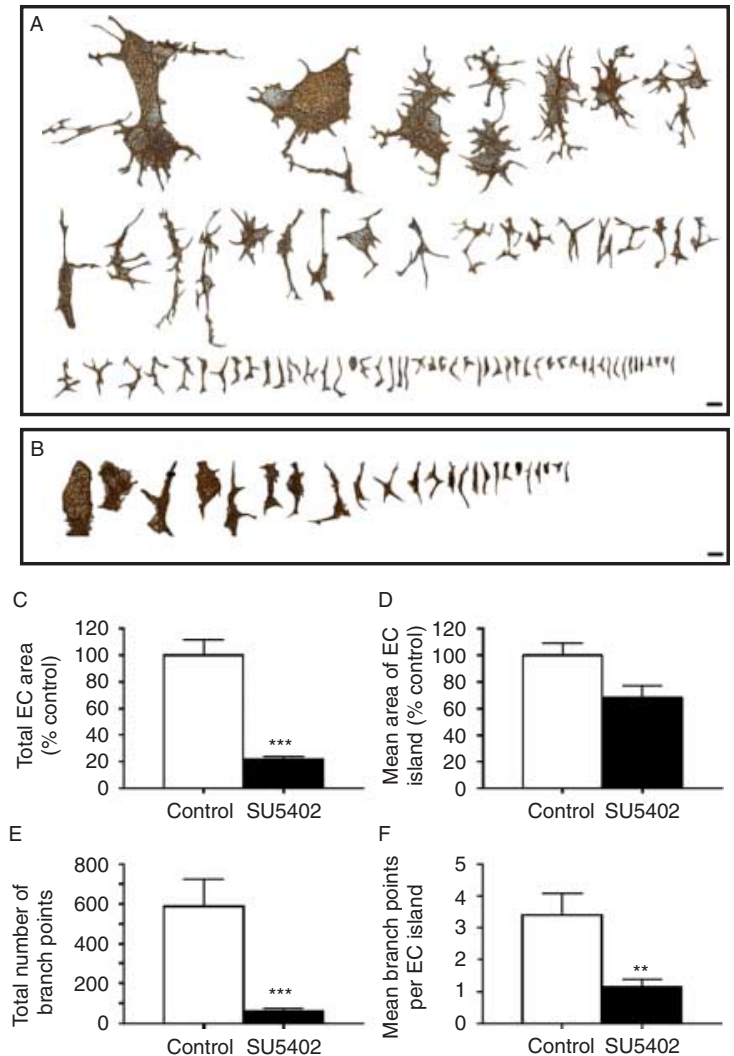

Figure 4 Bovine luteal cells were treated with control medium or plus $1 \mu \mathrm{M}$ SU5402 (FGFR1 inhibitor) for days 3-6. Endothelial cells (EC) were immunostained for von Willebrand factor after 6 days of culture and Branch/End image analysis performed. Representative images of endothelial cell islands observed after (A) control or (B) $1 \mu \mathrm{M}$ SU5402 treatment and sorted by island area are shown. The effects of $1 \mu \mathrm{M}$ SU5402 treatment on (C) the total area of endothelial cells, (D) the mean area of each endothelial cell island, $(E)$ the total number of branch points and $(\mathrm{F})$ the mean number of branch points per endothelial cell island are shown. Bars represent $100 \mu \mathrm{m}$. Data are mean + S.E.M. Significant differences between the groups are indicated by asterisks (***P<0.001 and $\left.{ }^{* *} P<0.01\right)$.

Sprouting is a highly complex and coordinated process involving a number of molecular signals and cellular phenotype changes (Holderfield \& Hughes 2008). There is strong evidence that the Notch signalling pathway plays a key role in endothelial sprouting by determining endothelial cell phenotype and thus number of endothelial tip cells (Gridley 2007). The Notch signalling pathway comprises Notch receptors (Notch 1-4) that interact with several Notch ligands (Jagged (JAG) 1 and 2; Delta like (DLL) 1, 3 and 4). All the ligands are transmembrane type proteins and thus Notch signalling is mediated by cell-cell interactions. It is widely recognised that endothelial tip cells express DLL4 which then interacts with Notch receptors on adjoining endothelial cells converting them into stalk cells (Eilken \& Adams 2010). In contrast, JAG1 is strongly expressed in stalk cells and antagonises DLL4-mediated Notch signalling and thereby controls the number of tip cells and sprouts. Thus, it is likely that the dynamic switching between endothelial tip and stalk cells is transient and reversible and depends on the balance between JAG1 and DLL4 expression. It has been shown that VEGFA promotes the formation of endothelial tip cells by inducing DLL4 expression (Eilken \& Adams 2010). However, FGF2 is more likely to exert its effects by up-regulating Notch4 expression (Wu \& Bresnick 2007) and modulating the action of Jagged. Indeed, FGF2-induction of endothelial cell sprouting was potentiated by treatment with an antisense oligomer to Jagged in bovine microvascular endothelial cells (Zimrin et al. 1996).

It is also likely that FGF2 will interact with other important regulatory factors. Members of the transforming growth factor $\beta$ (TGFB) superfamily can have important angiogenic effects, including a synergistic effect of TGFB on endothelial branching following FGF stimulation (Pepper et al. 1993). Other pathways that may provide important guidance cues such as the Angiopoietin/Tie (Thomas \& Augustin 2009), Slit/Roundabout (Robo) (Legg et al. 2008) and WNT-signalling (Franco et al. 2009) systems may also integrate with FGF signals.

In this study, the maximal reduction in endothelial cell networks in response to FGF2 inhibition was observed between days 3 and 6, whilst in vivo luteal FGF2 content was sixfold lower on days 5 vs 2 of the oestrous cycle (Robinson et al. 2007). Any difference in timing is likely to reflect a lag time as cells establish in culture and relatively broad windows of both inhibitor treatment and timed $\mathrm{CL}$ collection. In addition, small variations in starting material might be expected to subtly shift the timing of events in culture relative to the treatment windows.

No inhibitor treatment window was able to completely abolish endothelial cell growth $(81 \%$ reduction), indeed no treatment window was able to match the 95\% reduction in endothelial cell networks previously observed following SU5402 inhibitor treatment at the same concentration throughout culture (Woad et al. 2009). This study suggests that the 95\% reduction previously observed was primarily the result of cumulative inhibition from days 0 to 6 , with little influence in the final days of culture.

The significant reductions in the total area of VWF immunostaining following SU5402 treatment reflect primarily a decrease in the number of endothelial cell networks observed on day 9, rather than the area of each network. This is not as a result of a generalised cellular toxicity since considerable cell density and hence cell proliferation was apparent by day 9. Furthermore, progesterone production increases during culture and was previously unaffected by SU5402 treatment, suggestive of a healthy steroidogenic cell population (Robinson et al. 2008, Woad et al. 2009). Nor does there appear to be endothelial-specific toxicity, since treatment on days 6-9 resulted in no reduction in the total 
area of VWF staining vs controls. Since the total area of endothelial cell networks was significantly reduced on days $3-6$ as well as days $0-3$, it is also likely that reductions are not merely the result of endothelial cells failing to establish and/or recover from tissue disruption, and subsequently proliferate. A reduction in the number of networks could however be due to increased physiological cell death or apoptosis resulting from a period of growth factor deprivation. FGF2 has been shown to act as a survival factor, protecting endothelial cells from cell death in vitro (Fuks et al. 1994, Karsan et al. 1997) and inhibition of this survival signal might result in marked endothelial cell loss. Indeed, endothelial cells may be particularly sensitive to the loss of growth factor support during tubule initiation. A requirement for positive survival signals in luteal development has been suggested (Hojo et al. 2010) and apoptotic endothelial cells have been localised in primate corpora lutea following VEGFA-suppression (Dickson et al. 2001). In addition, the FGF2-independence that develops over time in culture in this study may reflect an increasing resistance to endothelial cell apoptosis that occurs as vessel-like structures mature and recruit perivascular cells (Benjamin et al. 1998, 1999).

Apoptosis is an essential component of structural luteolysis (Stocco et al. 2007) and is first evident in luteal endothelial cells (Sawyer et al. 1990). Interestingly, endothelial cell apoptosis may not only be involved in tissue regression; programmed cell death may also contribute to the formation of vascular-like endothelial cell networks in vitro and blocking apoptosis leads to disrupted vascular growth in vivo (Segura et al. 2002, Affara et al. 2007). The critical balance of pro- and antiapoptotic signals that must be maintained for appropriate luteal vessel development therefore warrants further investigation.

The reduction in the total area of endothelial cell networks after treatment with SU5402 on days 3-6 was similar whether cells were collected on day 6 or 9 of culture compared with time-matched controls. The time course experiment suggests that networks continue to develop between days 6 and 9 and so the area of networks would be expected to be different between the controls. This aside, the extent of the effect of SU5402 treatment was similar at around $80 \%$ irrespective of time of collection and suggests that neither is there a period of endothelial catch up between days 6 and 9 post-treatment, nor is there a further detrimental effect on endothelial cell growth that lasts beyond the treatment period.

Treatment with SU1498 to specifically inhibit VEGFR2 activity did not result in any significant effect on endothelial cell network growth vs controls at any time point. This is in contrast with the $60 \%$ reduction in total area of VWF immunostaining that was observed following blanket treatment with SU1498 at the same concentration for days 0-9 of culture (Woad et al. 2009).
Interestingly, the delivery of anti-VEGF antibodies directly into the bovine $\mathrm{CL}$ for 7 days post-ovulation reduced luteal volume by around $50 \%$ vs controls (Yamashita et al. 2008) and in the marmoset, treatment with anti-VEGF antibodies for 10 days also reduced endothelial cell area by around 50\% (Fraser et al. 2000). This study suggests that there is no specific period of sensitivity to VEGFA, rather that at most a small response may have occurred during each window. We have previously shown limited temporal variations in luteal VEGFA concentrations throughout the bovine oestrous cycle (Robinson et al. 2007). An important role for VEGFA in luteal angiogenesis is suggested both by luteal expression (Berisha et al. 2000, Robinson et al. 2007) and by markedly compromised luteal form and function in response to VEGFA-suppression (Ferrara et al. 1998, Zimmermann et al. 2001, Fraser et al. 2005, Yamashita et al. 2008). Indeed, VEGF antagonist treatment caused near total suppression of luteal angiogenesis in the rat, although this may be the result of effects on both follicular and luteal development, since the antagonist was given before the ovarian stimulation regime (Ferrara et al. 1998). However, there was no effect of VEGF inhibition on endothelial cell area at any treatment window in this study. This is similar to observations in the marmoset, where short-term treatment for 3 days with antibodies against VEGF also had no effect on endothelial cell area (Fraser et al. 2000). An alternative explanation is that endothelial cells were able to subsequently recover from any short-term inhibitory treatment during days $0-3$ or 3-6 and hence no difference in VWF staining was observed on day 9.

VEGF ligands bind to three receptors, namely VEGFR1, VEGFR2 and VEGFR3 (Cebe-Suarez et al. 2006, Olsson et al. 2006). VEGFR1 is crucial to embryonic blood vessel development, but displays weak kinase activity in comparison with VEGFR2 that is considered to be the major VEGFR in angiogenic signalling. Indeed, VEGFR2 not VEGFR1 was responsible for endothelial tube formation in bovine microvascular endothelial cells (Yang et al. 2001). The expression of mRNA encoding VEGFR3 has been detected in the ovary (Brown et al. 2010) including the primate $\mathrm{CL}$, where expression levels were highest around the midluteal phase (Xu \& Stouffer 2009), however signalling via VEGFR3 is considered of primary importance in the lymphatic vasculature and lymphangiogenesis.

In conclusion, this study identified key windows of sensitivity to FGF2 inhibition and supports our hypothesis that inhibition of FGF2 activity is most critical during the early periods of luteal angiogenesis, specifically during endothelial cell sprouting and tubule initiation. FGF2 is a dynamic modulator of angiogenesis in the bovine $\mathrm{CL}$, whilst VEGFA plays a more constitutive role throughout the luteal lifespan. 


\section{Materials and Methods}

\section{Materials}

All materials were purchased from Fisher Scientific, Loughborough, UK unless stated.

\section{Tissue collection}

Bovine ovaries were collected from a local slaughterhouse and stored in warmed $1 \times$ PBS for transport to the laboratory. Early corpora lutea (days 1-4) were selected based on established morphological criteria (Ireland et al. 1980) and surrounding tissue trimmed away.

\section{Luteal angiogenesis culture system}

Cells (including luteal steroidogenic, endothelial, pericytes and fibroblasts) were prepared as described previously (Robinson et al. 2008). In brief, corpora lutea were dispersed by collagenase and DNase digestion. Cells were then washed and subsequently grown in a specialised endothelial basal medium (EBM-2; Lonza, Verviers, Belgium) to which human epidermal growth factor, $\mathrm{LR}^{3}$ insulin-like growth factor 1 , hydrocortisone, ascorbic acid, gentamicin and heparin were added as per manufacturer's instructions. In addition, medium was supplemented with LH (5 ng/ml; AFP11743B, biopotency 1.06x oLH NIDDK-1-2; a gift from Dr A F Parlow, NIDDK, Torrance, CA, USA), 100 units $/ \mathrm{ml}$ penicillin, $10 \mu \mathrm{g} / \mathrm{ml}$ streptomycin, $10 \mu \mathrm{g} / \mathrm{ml}$ insulin, $5.5 \mu \mathrm{g} / \mathrm{ml}$ transferrin, $5 \mathrm{ng} / \mathrm{ml}$ selenium (all Sigma-Aldrich Co. Ltd.) and 2\% (v/v) foetal bovine serum (Lonza). All wells were further supplemented with $1 \mathrm{ng} / \mathrm{ml}$ VEGFA and $1 \mathrm{ng} / \mathrm{ml}$ FGF2 (Lonza). Cell number and viability were determined by trypan blue exclusion and cells were plated at $2 \times 10^{5}$ viable cells per well in a 12 -well plate onto fibronectincoated cover slips prepared as detailed previously (Robinson et al. 2008). Cells were cultured at $39{ }^{\circ} \mathrm{C}$ in a humidified incubator in $5 \% \mathrm{CO}_{2}, 95 \%$ air and medium changed after 1, 3, 5 and 7 days of culture. Cells were fixed in acetone:methanol (1:1) at $4{ }^{\circ} \mathrm{C}$ for 5 min before immunostaining.

\section{Time course of endothelial cell growth in culture}

Luteal cells were prepared and plated as described above to investigate the growth of endothelial cell networks over time ( $n=5$ cultures, one CL per culture). Cover slips $(n=3$ per culture, per time point) were removed from the culture plate and cells were then fixed in acetone:methanol $(1: 1)$ at $4{ }^{\circ} \mathrm{C}$ for 5 min after 6,12 and $18 \mathrm{~h}$ (day 1 ) in culture and then subsequently every day until day 9 . Endothelial cells were then immunolocalised using VWF as described below and the patterns of endothelial cell growth assessed.

\section{Effect of inhibitor treatments on endothelial cell network formation}

Luteal cells were prepared and plated as described above to investigate the effect of FGF2 or VEGFA inhibitor treatment during different phases of endothelial cell network formation
( $n=5$ cultures, one $\mathrm{CL}$ per culture). Cells were grown in standard supplemented medium (EBM-2; Lonza) in the presence of $1 \mathrm{ng} / \mathrm{ml}$ VEGFA and $1 \mathrm{ng} / \mathrm{ml}$ FGF2 (control), with or without $1 \mu \mathrm{M}$ SU5402 (specific FGFR1 inhibitor) or $2 \mu \mathrm{M}$ SU1498 (specific VEGFR2 inhibitor). Treatment windows were selected based on the time course of endothelial cell growth. Cells were treated with inhibitors in triplicate from days 0 to 3 (island formation), days 3-6 (vascular sprouting and tubule initiation) or days 6-9 (network development) of culture, and subsequently fixed on day 9 in acetone:methanol $(1: 1)$ at $4{ }^{\circ} \mathrm{C}$ for 5 min before immunostaining.

SU5402 inhibits FGFR1 kinase activity and downstream signalling by direct interactions with the FGFR1 catalytic domain (Mohammadi et al. 1997), and has been widely used as a specific FGF2-antagonist and inhibitor of FGF2-mediated angiogenesis (Numata et al. 2006, Nicoli et al. 2008). SU1498 specifically inhibits VEGFR2 phosphorylation, resulting in reduced endothelial cell proliferation in vitro, and the inhibition of angiogenesis in vivo (Strawn et al. 1996, Katanasaka et al. 2008). SU5402 and SU1498 were used at doses that have previously been shown to inhibit angiogenesis in this culture system ( 1 and $2 \mu \mathrm{M}$, respectively), in experiments that were performed in an identical manner to this study (Woad et al. 2009). The inhibitors (Calbiochem, Merck Chemicals Ltd.) were first dissolved in DMSO and then subsequently diluted in media, to give a final DMSO concentration of $0.1 \%(\mathrm{v} / \mathrm{v})$ and $0.1 \%$ DMSO was also added to control wells.

To further investigate the effect of SU5402 treatment on days 3-6, luteal cells were prepared, plated and treated with $1 \mu \mathrm{M}$ SU5402 as described above ( $n=5$ cultures) but collected and fixed immediately post-treatment on day 6 before standard VWF immunostaining and analysis.

\section{Immunocytochemistry for VWF}

Endothelial cells were immunolocalised using VWF as a specific endothelial cell marker, following methods previously validated and described (Robinson et al. 2008, Woad et al. 2009). In brief, endogenous peroxidase activity was blocked using $3 \%(\mathrm{v} / \mathrm{v})$ hydrogen peroxide in methanol, and nonspecific binding was blocked using $20 \%$ (v/v) normal goat serum (Sigma-Aldrich Co. Ltd.). Cover slips were incubated with $4 \mu \mathrm{g} / \mathrm{ml}$ rabbit anti-human VWF primary antibody (Dako UK Ltd., Ely, UK) overnight in a humidified chamber, followed by detection using a biotinylated goat anti-rabbit secondary antibody and the Vectastain ABC method (Vector Laboratories Ltd., Peterborough, UK) with diaminobenzidine (Vector Laboratories Ltd.) as peroxidase substrate.

\section{Image analysis}

Positive staining for VWF was quantified as described previously (Woad et al. 2009) with minor modifications. In brief, sections were viewed under $5 \times$ magnification using a Leica DM 4000B microscope (Leica Microsystems Ltd., Milton Keynes, UK) and QImaging micropublisher 5.0 RTV colour camera (QImaging (UK) Ltd., St Helens, UK). Images were captured and analysed using Image Pro-Plus 6.0 
(Media Cybernetics, Wokingham, UK). Two wells per treatment per culture were selected at random for analysis and images were acquired from 20 fields of view, which were tiled to create a composite image for processing. Areas of positive staining with a tubule-like appearance of $>150 \mu \mathrm{m}^{2}$ were highlighted, smoothed and any holes in staining removed. Image analysis then determined the total area of VWF staining, the number of endothelial cell networks and the area and length of each individual network. Additional image analysis was performed to determine potential changes in the pattern of endothelial cell growth observed on day 6 after treatment with SU5402, using an automated measure of branching (Branch/End feature, Image Pro-Plus 6; Masri et al. 2007).

\section{Statistical analysis}

Randomised block one-way ANOVA followed by Bonferroni's multiple comparison test were used to compare the total area and length of endothelial cell networks, mean network number and mean area per network between experimental groups on day 9 , and the total area of endothelial cell islands, mean island number, mean area per island, total branch points and branch points per island between experimental groups on day 6 . The variables were blocked by culture, with treatment as the factor. All data were examined for normality and heterogeneity of variance and were log transformed where appropriate (Genstat 12, VSN International, Hemel Hempstead, UK).

\section{Declaration of interest}

The authors declare that there is no conflict of interest that could be perceived as prejudicing the impartiality of the research reported.

\section{Funding}

This work was supported by BBSRC grant BB/F002998 and Pfizer.

\section{Acknowledgements}

We are grateful to the staff of the University of Nottingham for their assistance with sample collection and analysis.

\section{References}

Affara M, Dunmore B, Savoie C, Imoto S, Tamada Y, Araki H, CharnockJones DS, Miyano S \& Print C 2007 Understanding endothelial cell apoptosis: what can the transcriptome, glycome and proteome reveal? Philosophical Transactions of the Royal Society of London. Series B, Biological Sciences 362 1469-1487. (doi:10.1098/rstb.2007.2129)

Benjamin LE, Hemo I \& Keshet E 1998 A plasticity window for blood vessel remodelling is defined by pericyte coverage of the preformed endothelial network and is regulated by PDGF-B and VEGF. Development 125 1591-1598.

Benjamin LE, Golijanin D, Itin A, Pode D \& Keshet E 1999 Selective ablation of immature blood vessels in established human tumors follows vascular endothelial growth factor withdrawal. Journal of Clinical Investigation 103 159-165. (doi:10.1172/JCl5028)
Berisha B, Schams D, Kosmann M, Amselgruber W \& Einspanier R 2000 Expression and tissue concentration of vascular endothelial growth factor, its receptors, and localization in the bovine corpus luteum during estrous cycle and pregnancy. Biology of Reproduction 63 1106-1114. (doi:10.1095/biolreprod63.4.1106)

Bernard-Pierrot I, Ricol D, Cassidy A, Graham A, Elvin P, Caillault A, Lair S, Broet P, Thiery J-P \& Radvanyi F 2004 Inhibition of human bladder tumour cell growth by fibroblast growth factor receptor $2 b$ is independent of its kinase activity. Involvement of the carboxy-terminal region of the receptor. Oncogene 23 9201-9211. (doi:10.1038/sj.onc.1208150)

Brown HM, Robker RL \& Russell DL 2010 Development and hormonal regulation of the ovarian lymphatic vasculature. Endocrinology 151 5446-5455. (doi:10.1210/en.2010-0629)

Cebe-Suarez S, Zehnder-Fjallman A \& Ballmer-Hofer K 2006 The role of VEGF receptors in angiogenesis; complex partnerships. Cellular and Molecular Life Sciences 63 601-615. (doi:10.1007/s00018-005-5426-3)

Dickson SE, Bicknell R \& Fraser HM 2001 Mid-luteal angiogenesis and function in the primate is dependent on vascular endothelial growth factor. Journal of Endocrinology 168 409-416. (doi:10.1677/joe.0. 1680409)

Eilken HM \& Adams RH 2010 Dynamics of endothelial cell behavior in sprouting angiogenesis. Current Opinion in Cell Biology 22 617-625. (doi:10.1016/j.ceb.2010.08.010)

Ferrara N 2004 Vascular endothelial growth factor: basic science and clinical progress. Endocrine Reviews 25 581-611. (doi:10.1210/er.20030027)

Ferrara N, Chen H, Davis-Smyth T, Gerber H-P, Nguyen T-N, Peers D, Chisholm V, Hillan KJ \& Schwall RH 1998 Vascular endothelial growth factor is essential for corpus luteum angiogenesis. Nature Medicine 4 336-340. (doi:10.1038/nm0398-336)

Franco CA, Liebner S \& Gerhardt H 2009 Vascular morphogenesis: a Wnt for every vessel? Current Opinion in Genetics \& Development 19 476-483. (doi:10.1016/j.gde.2009.09.004)

Fraser HM, Dickson SE, Lunn SF, Wulff C, Morris KD, Carroll VA \& Bicknell R 2000 Suppression of luteal angiogenesis in the primate after neutralization of vascular endothelial growth factor. Endocrinology 141 995-1000. (doi:10.1210/en.141.3.995)

Fraser HM, Wilson H, Morris KD, Swanston I \& Wiegand SJ 2005 Vascular endothelial growth factor trap suppresses ovarian function at all stages of the luteal phase in the macaque. Journal of Clinical Endocrinology and Metabolism 90 5811-5818. (doi:10.1210/jc.2005-1199)

Fuks Z, Persaud RS, Alfieri A, McLoughlin M, Ehleiter D, Schwartz JL, Seddon AP, Cordon-Cardo C \& Haimovitz-Friedman A 1994 Basic fibroblast growth factor protects endothelial cells against radiationinduced programmed cell death in vitro and in vivo. Cancer Research 54 2582-2590.

Gerhardt $H$, Golding $M$, Fruttiger $M$, Ruhrberg C, Lundkvist A, Abramsson A, Jeltsch M, Mitchell C, Alitalo K, Shima D et al. 2003 VEGF guides angiogenic sprouting utilizing endothelial tip cell filopodia. Journal of Cell Biology 161 1163-1177. (doi:10.1083/jcb. 200302047)

Gospodarowicz D, Massoglia S, Cheng J \& Fujii DK 1986 Effect of fibroblast growth factor and lipoproteins on the proliferation of endothelial cells derived from bovine adrenal cortex, brain cortex, and corpus luteum capillaries. Journal of Cellular Physiology 127 121-136. (doi:10.1002/ jcp.1041270116)

Grand EK, Chase AJ, Heath C, Rahemtulla A \& Cross NCP 2004 Targeting FGFR3 in multiple myeloma: inhibition of $\mathrm{t}(4 ; 14)$-positive cells by SU5402 and PD173074. Leukemia 18 962-966. (doi:10.1038/sj.leu. 2403347)

Gridley T 2007 Notch signaling in vascular development and physiology. Development 134 2709-2718. (doi:10.1242/dev.004184)

Guerra DM, Giometti IC, Price CA, Andrade PB, Castilho AC, Machado MF, Ripamonte P, Papa PC \& Buratini J 2008 Expression of fibroblast growth factor receptors during development and regression of the bovine corpus luteum. Reproduction, Fertility and Development 20 659-664. (doi:10.1071/RD07114)

Hojo T, Al-Zi'abi MO, Komiyama J, Manabe N, Acosta TJ \& Okuda K 2010 Expression and localization of CFLIP, an anti-apoptotic factor, in the bovine corpus luteum. Journal of Reproduction and Development $\mathbf{5 6}$ 230-235. (doi:10.1262/jrd.09-185S) 
Holderfield MT \& Hughes CCW 2008 Crosstalk between vascular endothelial growth factor, Notch, and transforming growth factor- $\beta$ in vascular morphogenesis. Circulation Research 102 637-652. (doi:10. 1161/CIRCRESAHA.107.167171)

Ireland JJ, Murphee RL \& Coulson PB 1980 Accuracy of predicting stages of bovine estrous cycle by gross appearance of the corpus luteum. Journal of Dairy Science 63 155-160. (doi:10.3168/jds.S0022-0302(80)82901-8)

Karsan A, Yee E, Poirier GG, Zhou P, Craig R \& Harlan JM 1997 Fibroblast growth factor-2 inhibits endothelial cell apoptosis by $\mathrm{Bcl}$-2-dependent and independent mechanisms. American Journal of Pathology 151 $1775-1784$.

Katanasaka Y, Ida T, Asai T, Maeda N \& Oku N 2008 Effective delivery of an angiogenesis inhibitor by neovessel-targeted liposomes. International Journal of Pharmaceutics 360 219-224. (doi:10.1016/j.ijpharm.2008. 04.046)

Larson SF, Butler WR \& Currie WB 1997 Reduced fertility associated with low progesterone postbreeding and increased milk urea nitrogen in lactating cows. Journal of Dairy Science 80 1288-1295. (doi:10.3168/ jds.S0022-0302(97)76058-2)

Legg JA, Herbert JM, Clissold P \& Bicknell R 2008 Slits and Roundabouts in cancer, tumour angiogenesis and endothelial cell migration. Angiogenesis 11 13-21. (doi:10.1007/s10456-008-9100-x)

Mann GE \& Lamming GE 2001 Relationship between maternal endocrine environment, early embryo development and inhibition of the luteolytic mechanism in cows. Reproduction 121 175-180. (doi:10.1530/rep.0. 1210175)

Masri FA, Xu W, Comhair SAA, Asosingh K, Koo M, Vasanji A, Drazba J, Anand-Apte B \& Erzurum SC 2007 Hyperproliferative apoptosisresistant endothelial cells in idiopathic pulmonary arterial hypertension. American Journal of Physiology. Lung Cellular and Molecular Physiology 293 L548-L554. (doi:10.1152/ajplung.00428.2006)

Mohammadi M, McMahon G, Sun L, Tang C, Hirth P, Yeh BK, Hubbard SR \& Schlessinger J 1997 Structures of the tyrosine kinase domain of fibroblast growth factor receptor in complex with inhibitors. Science $\mathbf{2 7 6}$ 955-960. (doi:10.1126/science.276.5314.955)

Nicoli S, De Sena G \& Presta M 2008 Fibroblast growth factor 2-induced angiogenesis in zebrafish: the zebrafish yolk membrane (ZFYM) angiogenesis assay. Journal of Cellular and Molecular Medicine 13 2061-2068. (doi:10.1111/j.1582-4934.2008.00432.x)

Numata Y, Terui T, Okuyama R, Hirasawa N, Sugiura Y, Miyoshi I, Watanabe T, Kuramasu A, Tagami H \& Ohtsu H 2006 The accelerating effect of histamine on the cutaneous wound-healing process through the action of basic fibroblast growth factor. Journal of Investigative Dermatology 126 1403-1409. (doi:10.1038/sj.jid.5700253)

Olsson A-K, Dimberg A, Kreuger J \& Claesson-Welsh L 2006 VEGF receptor signalling - in control of vascular function. Nature Reviews. Molecular Cell Biology 7 359-371. (doi:10.1038/nrm1911)

Ornitz DM, Xu J, Colvin JS, McEwen DG, MacArthur CA, Coulier F, Gao G \& Goldfarb M 1996 Receptor specificity of the fibroblast growth factor family. Journal of Biological Chemistry 271 15292-15297. (doi:10.1074/ jbc.271.25.15292)

Parsons-Wingerter P, Elliott KE, Clark JI \& Farr AG 2000 Fibroblast growth factor-2 selectively stimulates angiogenesis of small vessels in arterial tree. Arteriosclerosis, Thrombosis, and Vascular Biology 20 1250-1256. (doi:10.1161/01.ATV.20.5.1250)

Pepper MS, Vassalli JD, Orci L \& Montesano R 1993 Biphasic effect of transforming growth factor- $\beta$ on in vitro angiogenesis. Experimental Cell Research 204 356-363. (doi:10.1006/excr.1993.1043)

Presta M, Dell'Era P, Mitola S, Moroni E, Ronca R \& Rusnati M 2005 Fibroblast growth factor/fibroblast growth factor receptor system in angiogenesis. Cytokine \& Growth Factor Reviews 16 159-178. (doi:10. 1016/j.cytogfr.2005.01.004)

Robinson RS, Nicklin LT, Hammond AJ, Schams D, Hunter MG \& Mann GE 2007 Fibroblast growth factor 2 is more dynamic than vascular endothelial growth factor A during the follicle-luteal transition in the cow. Biology of Reproduction 77 28-36. (doi:10.1095/biolreprod.106. 055434)
Robinson RS, Hammond AJ, Mann GE \& Hunter MG 2008 A novel physiological culture system that mimics luteal angiogenesis. Reproduction 135 405-413. (doi:10.1530/REP-07-0370)

Rousseau BT, Dubayle D, Sennlaub F, Jeanny J-C, Costet P, Bikfalvi A \& Javerzat $\mathbf{S} 2000 \mathrm{Neural}$ and angiogenic defects in eyes of transgenic mice expressing a dominant-negative FGF receptor in the pigmented cells. Experimental Eye Research 71 395-404. (doi:10.1006/exer.2000.0892)

Sawyer HR, Niswender KD, Braden TD \& Niswender GD 1990 Nuclear changes in ovine luteal cells in response to PGF2[alpha]. Domestic Animal Endocrinology 7 229-237. (doi:10.1016/0739-7240 (90)90029-Y)

Segura I, Serrano A, De Buitrago GG, Gonzalez MA, Abad JL, Claveria C, Gomez L, Bernad A, Martinez AC \& Riese HH 2002 Inhibition of programmed cell death impairs in vitro vascular-like structure formation and reduces in vivo angiogenesis. FASEB Journal 16 833-841. (doi:10. 1096/fj.01-0819com)

Stocco C, Telleria C \& Gibori G 2007 The molecular control of corpus luteum formation, function, and regression. Endocrine Reviews 28 117-149. (doi:10.1210/er.2006-0022)

Strawn LM, McMahon G, App H, Schreck R, Kuchler WR, Longhi MP, Hui TH, Tang C, Levitzki A, Gazit A et al. 1996 Flk-1 as a target for tumor growth inhibition. Cancer Research 56 3540-3545.

Thomas M \& Augustin H 2009 The role of the angiopoietins in vascular morphogenesis. Angiogenesis 12 125-137. (doi:10.1007/s10456-0099147-3)

Woad KJ, Hammond AJ, Hunter M, Mann GE, Hunter MG \& Robinson RS 2009 FGF2 is crucial for the development of bovine luteal endothelial networks in vitro. Reproduction 138 581-588. (doi:10.1530/REP-090030)

Wu J \& Bresnick EH 2007 Glucocorticoid and growth factor synergism requirement for Notch4 chromatin domain activation. Molecular and Cellular Biology 27 2411-2422. (doi:10.1128/MCB.02152-06)

Wulff C, Wilson H, Rudge JS, Wiegand SJ, Lunn SF \& Fraser HM 2001 Luteal angiogenesis: prevention and intervention by treatment with vascular endothelial growth factor trap(A40). Journal of Clinical Endocrinology and Metabolism 86 3377-3386. (doi:10.1210/jc.86.7. 3377)

Xu F \& Stouffer RL 2009 Existence of the lymphatic system in the primate corpus luteum. Lymphatic Research and Biology 7 159-168. (doi:10. 1089//rb.2009.0009)

Yamashita H, Kamada D, Shirasuna K, Matsui M, Shimizu T, Kida K, Berisha B, Schams D \& Miyamoto A 2008 Effect of local neutralization of basic fibroblast growth factor or vascular endothelial growth factor by a specific antibody on the development of the corpus luteum in the cow. Molecular Reproduction and Development 75 1449-1456. (doi:10. 1002/mrd.20878)

Yang S, Xin X, Zlot C, Ingle G, Fuh G, Li B, Moffat B, de Vos AM \& Gerritsen ME 2001 Vascular endothelial cell growth factor-driven endothelial tube formation is mediated by vascular endothelial cell growth factor receptor-2, a kinase insert domain-containing receptor. Arteriosclerosis, Thrombosis, and Vascular Biology 21 1934-1940. (doi:10.1161/hq1201.099432)

Zimmermann RC, Hartman T, Bohlen P, Sauer MV \& Kitajewski J 2001 Preovulatory treatment of mice with anti-VEGF receptor 2 antibody inhibits angiogenesis in corpora lutea. Microvascular Research 62 15-25. (doi:10.1006/mvre.2001.2312)

Zimrin AB, Pepper MS, McMahon GA, Nguyen F, Montesano R \& Maciag T 1996 An antisense oligonucleotide to the notch ligand jagged enhances fibroblast growth factor-induced angiogenesis in vitro. Journal of Biological Chemistry 271 32499-32502. (doi:10.1074/jbc.271.51. 32499)

Received 1 August 2011

First decision 22 August 2011

Revised manuscript received 24 September 2011

Accepted 13 October 2011 